\title{
Optimal shape control of piezolaminated beams with different boundary condition and loading using genetic algorithm
}

\author{
Kouider Bendine ${ }^{1} \cdot$ Rajan L. Wankhade ${ }^{2}$
}

Received: 28 March 2017 / Accepted: 4 October 2017/Published online: 17 October 2017

(C) The Author(s) 2017. This article is an open access publication

\begin{abstract}
Piezoelectric actuators are effectively used to control the response of light weight structures in shape, vibration and buckling. Optimization for the shape control of piezoelectric beam is the recent challenge which requires proper numerical technique to perform. The shape control of a composite beam using surface-bounded piezoelectric actuators has been investigated in the present work. The mathematical model is developed using twonode Timoshenko beam element coupling with the theory of linear piezoelectricity. First-order shear deformation theory is employed in the formulation to consider the effect of shear. In the analysis, the effect of the actuators position for different set of boundary conditions is investigated. For different boundary conditions which include clampedfree-, clamped-clamped- and simply supported beam, optimisation of piezoelectric patch location is investigated. Moreover, a genetic algorithm is adopted and implemented to optimize the required voltage to maintain the desired shape of the beam. This optimization technique is applied to different cases of composite beams with varying the boundary condition.
\end{abstract}

Rajan L. Wankhade

rajanw04@gmail.com

Kouider Bendine

kouider84@live.com

1 Mechanics of Structures and Solids Laboratory, Department of Mechanics, Faculty of Technology, DjillaliLiabès University of SidiBel-Abbès, BP 89, Cité Ben M'hidi, 22000 Sidibel-Abbès, Algeria

2 Applied Mechanics Department, Government College of Engineering, Nagpur, Maharashtra, India
Keywords Shape control · Piezolaminates beams · Genetic algorithm

\section{Introduction}

In recent years, the piezoelectric materials and structures have drawn much attention because of their potential advantage in sensing and actuating. They are considered as the most appropriate and perfect solution of many technical issues such as shape and vibration control, buckling control and noise reduction. They are also effectively used for crack detention, damage identification and structural health monitoring purposes. Smart piezolaminated composite beams with self-monitoring and control capabilities are of great technological interest due to the increasing requirements in structural engineering. The self-monitoring and controlling capability of smart beams have numerous applications in shape and vibration control of structures. One main objective of piezoelectric shape control is to optimize control parameters which include the number, location and size of the piezoelectric patches and the amount of electric potential to be applied so that the desired shapes are achieved or best matched. Optimization of such parameters and configurations of piezoelectric actuators for acquiring efficient and precise shape control has been an interesting subject of research in recent years which is investigated in the present work. For this, an accurate mathematical model for shape control is established by considering a critical factor for the performance of the smart beams. The determination of the optimal location of the piezoelectric actuators together with the optimal actuation voltages is worked out with optimization technique. 
Various theories for analysis of thick beams were developed in the earlier time. Kirchhoff (1850a, b) developed Classical plate theory which underestimates the deflection and overestimates natural frequencies and buckling loads. Mindlin (1951) developed displacementbased first-order shear deformation theory. In these theories, the transverse shear strain distribution is assumed to be constant through the thickness, and therefore, shear correction factor is required to account for the strain energy due to shear deformation.

In general, these shear correction factors are problem dependent. Crawley and Anderson (1990) studied detailed models of the piezoceramic actuation for beams. Tzou and Tseng (1990) investigated performance of distributed piezoelectric sensor/actuator design for dynamic measurement/control of distributed parameter systems based upon finite element approach. Pan et al. (1992) studied the response of a simply supported beam which is excited by a piezoelectric actuator. Onoda and Hanawa (1993) first time applied and presented improved simulated annealing approach for shape accuracy of space structures using genetic algorithm. Friedman and Kosmatka (1993) used an improved two-node Timoshenko beam finite element.

Thomson and Loughlan (1995) investigated active buckling control of some composite column using piezoceramic actuators. Fuller et al. (1996) studied active control of vibration. Dhonthireddy and Chandrashekhara (1996) worked on modeling and shape control of composite beams with embedded piezoelectric actuators. Chandrashekhara and Varadarajan (1997) stressed upon adaptive shape control of composite beams with piezoelectric actuators. Han et al. (1997) extended work to an experimental study of active vibration control of composite structures with a pizo-ceramic actuator and a piezo-film sensor. Reddy (1997) considered locking-free shear deformable beam finite elements. Aldraihem et al. (1997) studied distributed control of laminated beams with Timoshenko versus Euler-Bernoulli theory. Soares et al. (1999) proposed optimal design of piezolaminated structures. Faria and Almeida (1999) investigated enhancement of pre-buckling behavior of composite beams with geometric imperfections using piezoelectric actuators. Agrawal and Treanor (1999) provided the analytical and experimental results on optimal placement of piezoceramic actuators for shape control of beam structures. The objective achieved was to determine the optimum piezoelectric actuator locations and voltage to minimize the error between the desired shape and the achieved shape.

Aldraihem and Khdeir (2000) studied smart beams with extension and thickness-shear piezoelectric actuators. Bruch et al. (2000) investigated optimal piezo-actuator locations/lengths and applied voltage for shape control of beams. Wang (2002) observed buckling of column structures with a pair of piezoelectric layers. Kang et al. (2002) further put forth interaction of active and passive vibration control of laminated composite beams with piezoceramic sensors/actuators. Irschik Hans (2002) carried out review on static and dynamic shape control of structures by piezoelectric actuation. Kekana et al. (2003) considered shape control model for piezo-elastic structures based on divergence-free electric displacement International. Haupt et al. (2004) investigated practical genetic algorithms. da Mota et al. (2004) proposed the application of genetic algorithms for shape control with piezoelectric patches with an experimental comparison. Hadjigeorgiou et al. (2006) investigated shape control and damage identification of beams using piezoelectric actuation and genetic optimization. Kayacik et al. (2008) developed integral equation approach for piezopatch vibration control of beams with various types of damping. Krommer et al. (2008) proposed design of actuator networks for dynamic displacement tracking of beams. Azrar et al. (2008) performed nonlinear vibration analysis of actively loaded sandwich piezoelectric beams with geometric imperfections. Yu et al. (2009) focused on optimal shape control of a beam using piezoelectric actuators with low control voltage. Dhuri and Seshu (2009) used multi-objective optimization technique for piezo-actuator placement and sizing using genetic algorithm. Kucuk et al. (2011) used optimal vibration control to piezolaminated smart beams by the maximum principle. Bajoria and Wankhade (2012) effectively employed finite element method for free vibration analysis of simply supported plates. Simply supported plates were provided with piezoelectric patches for controlling the response in vibration. Takács et al. (2012) put model predictive vibration control with efficient constrained MPC vibration control for lightly damped mechanical structures. Wankhade and Bajoria (2012) studied stability of simply supported smart piezolaminated composite plates using finite element method. BeheshtiAval et al. (2013) developed finite element model based on coupled refined high-order global-local theory for static analysis of electromechanical-embedded shear-mode piezoelectric sandwich composite beams with various widths. Wankhade and Bajoria (2013a, b) focused on buckling analysis of piezolaminated plates using higherorder shear deformation theory. Elshafei and Alraiess (2013) studied modeling and analysis of smart piezoelectric beams using simple higher-order shear deformation theory. Wankhade and Bajoria (2013a, b) carried out free vibration and stability analysis of piezolaminated plates using finite element method. Bajoria and Wankhade (2015) further demonstrated vibration of cantilever piezolaminated beam with extension and shear-mode piezo-actuators. Bendine and Wankhade (2016) proposed vibration 
control of FGM piezoelectric plate based on LQR genetic search. Wankhade and Bajoria (2016) investigated shape control and vibration analysis of piezolaminated plates subjected to electromechanical loading. Wankhade and Bajoria (2017) further proposed numerical optimization of piezolaminated beams subjected to static and dynamic excitations. For these different models of beams with varying geometry and boundary conditions are developed.

In this paper, we present an efficient finite element approach based on shear deformable beam theory for the case of laminated beam with bonded piezoelectric actuators. The developed model is used to investigate the shape control of composite beam with three sets of boundary condition clamped-free (C-F), clamped-clamped (C-C) and simply supported (S-S). The effect of the actuator locations on the beam shape is presented. For final study, the required voltage to maintain a desired shape of beam is optimized using genetic algorithm.

\section{Constitutive equations and mathematical modeling}

\section{Displacement function}

The displacement field equations at any point through the thickness of the beam based on Timoshenko's beam theory (Reddy 1997; Hadjigeorgiou et al. 2006; Elshafei and Alraiess 2013) are presented by:

$u(x, z, t)=z \varphi_{x}(x, t)$

$w(x, z, t)=w_{0}(x, t)$

where $w_{0}$ is the transverse deflection of the mid-plane point, and $\varphi_{x}$ denotes the rotation angle along the $x$-axis.

Using Eq. (1), the strain components can be expressed as:

$\varepsilon_{x x}=z \frac{\partial \varphi_{x}}{\partial x}$

$\gamma_{x z}=\varphi_{x}+\frac{\partial w_{0}}{\partial x}$

The strain vector can be rewritten under the following matrix form:

$\left\{\begin{array}{l}\varepsilon_{x x} \\ \gamma_{x z}\end{array}\right\}=\left[\begin{array}{cc}0 & z \frac{\partial}{\partial x} \\ \frac{\partial}{\partial x} & 1\end{array}\right]\left(\begin{array}{l}w_{0} \\ \varphi_{x}\end{array}\right)$

The coupling relationship between the electrical and mechanical behavior (Tzou and Tseng 1990) can be described by

$$
\begin{aligned}
& \left\{\begin{array}{c}
\sigma_{x x} \\
\sigma_{y y} \\
\sigma_{z z} \\
\tau_{y z} \\
\tau_{x z} \\
\tau_{x y} \\
D_{x} \\
D_{y} \\
D_{z}
\end{array}\right\}=\left[\begin{array}{cccccc}
Q_{11} & Q_{21} & 0 & 0 & 0 & 0 \\
Q_{21} & Q_{22} & 0 & 0 & 0 & 0 \\
0 & 0 & Q_{33} & 0 & 0 & 0 \\
0 & 0 & 0 & Q_{44} & 0 & 0 \\
0 & 0 & 0 & 0 & Q_{55} & 0 \\
0 & 0 & 0 & 0 & 0 & Q_{66} \\
0 & 0 & 0 & 0 & e_{15} & 0 \\
0 & 0 & 0 & e_{24} & 0 & 0 \\
e_{31} & e_{32} & e_{33} & 0 & 0 & 0
\end{array}\right]\left\{\begin{array}{c}
\varepsilon_{x x} \\
\varepsilon_{y y} \\
\varepsilon_{z z} \\
\gamma_{y z} \\
\gamma_{x z} \\
\gamma_{x y}
\end{array}\right\} \\
& +\left[\begin{array}{ccc}
0 & 0 & -e_{31} \\
0 & 0 & -e_{32} \\
0 & 0 & -e_{33} \\
0 & -e_{24} & 0 \\
-e_{15} & 0 & 0 \\
0 & 0 & 0 \\
\epsilon_{11} & 0 & 0 \\
0 & \epsilon_{22} & 0 \\
0 & 0 & \epsilon_{33}
\end{array}\right]\left\{\begin{array}{l}
E_{x} \\
E_{y} \\
E_{z}
\end{array}\right\}
\end{aligned}
$$

where $\sigma$ is the stress vector, $D$ represents the electric displacement components, $E$ denotes the electric field component, $Q, e$ and $\in$ are the elastic, the piezoelectric coupling and the dielectric permittivity constants, respectively. In the case of a beam, the following assumptions are made:

The width in the $y$ direction is stress-free and the plane stress assumption is used. Therefore, it is possible to set

$\sigma_{y y}=\sigma_{z z}=\tau_{y z}=\tau_{x y}=0$

The electric field is neglected along the $x$ and $y$ directions $\left(E_{x}=E_{y}=0\right)$. Thus, only $D_{z}$ in Eq. (4) is considered.

Therefore the constitutive relation Eq. (4) is reduced to:

$$
\left\{\begin{array}{c}
\sigma_{x x} \\
\tau_{x z} \\
D_{z}
\end{array}\right\}=\left[\begin{array}{ccc}
Q_{11} & 0 & -e_{31} \\
0 & Q_{55} & 0 \\
e_{31} & 0 & \epsilon_{33}
\end{array}\right]\left\{\begin{array}{l}
\varepsilon_{x x} \\
\gamma_{x z} \\
E_{z}
\end{array}\right\}
$$

Assuming that the voltage is applied only in thickness direction, the electric field vector $\{E\}$ can be expressed as follows:

$E_{z}=\frac{V^{e}}{h_{a}}$

The Lagrangian ' $\Pi$ ' of the laminate beam can be obtained by the summation of the kinetic energy $\psi$ potential energy $\phi$ (including strain and electrical energies of the piezoelectric):

$\Pi=\int_{v}(\psi-\varphi) \mathrm{d} v$ 
Using Eqs. (1) and (2) and integrating over the crosssection of the beam, the kinetic energy term may be written as

$\psi=\frac{1}{2} \int_{y}\left\{\begin{array}{c}\dot{u} \\ \dot{w}\end{array}\right\}^{T}\left\{\begin{array}{c}\dot{u} \\ \dot{w}\end{array}\right\} \mathrm{d} v=\frac{1}{2}\left[\int_{0}^{L} I_{3}\left(\dot{\varphi}_{x}^{2}\right)+I_{1}(\dot{w})^{2}\right] \mathrm{d} x$

where

$\left(I_{1}, I_{3}\right)=\int_{s} \rho\left(1, z^{2}\right) \mathrm{d} s$

The potential energy $\phi$ (including strain and electrical energies of the piezoelectric) is expressed as

$$
\begin{aligned}
\phi= & \frac{1}{2} \int_{v}\{\varepsilon\}^{T}\{\sigma\} \mathrm{d} v \\
& +\frac{1}{2} \int_{v}\left(\{\varepsilon\}^{T}\{\sigma\}-\{E\}^{T}\{D\}\right) \mathrm{d} v
\end{aligned}
$$

Substituting Eqs. (1), (3), (5) and (6) in Eq. (10), the potential term may be rewritten as

$\phi=\int_{0}^{L}\left[\begin{array}{c}\frac{1}{2}(\mathrm{EI})\left(\frac{\partial \phi_{x}}{\partial x}\right)^{2}+\frac{1}{2}(\mathrm{GA})\left(\phi_{x}+\frac{\partial w}{\partial x}\right)^{2} \\ -M^{\mathrm{el}} \frac{\partial \phi_{x}}{\partial x}-\frac{1}{2}\left(\epsilon_{33 z} E_{z}^{2}\right)\end{array}\right] \mathrm{d} x$

with

$$
\begin{aligned}
& (\mathrm{EI})=\int_{S} z^{2} Q_{11} \mathrm{~d} s \\
& (\mathrm{GA})=k \int_{S} Q_{11} \mathrm{~d} s \\
& M^{\mathrm{el}}=\int_{S} \mathrm{ze}_{31} E_{z} \mathrm{~d} s
\end{aligned}
$$

The virtual work done by the external mechanical forces is given by

$\delta W_{e}=\int_{0}^{L_{e}}\left(\mathrm{qw}+m \varphi_{x}\right)$

Based on the equations above, the dynamic equations of the laminated beam structure can be derived using Hamilton's principle:

$\delta \int_{t_{1}}^{t_{2}}\left(\Pi-W_{e}\right)=0$

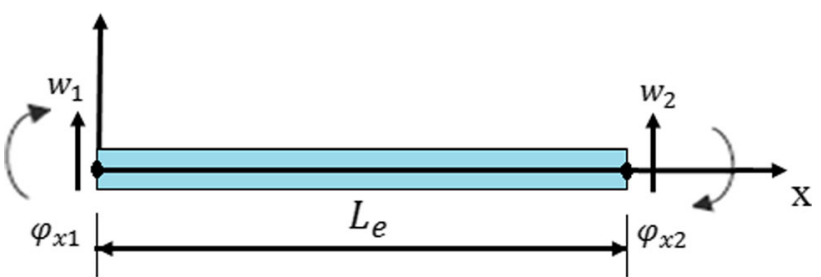

Fig. 1 Two degrees of freedom element beam

In this work, a two-node beam element (Fig. 1) with two mechanical degrees of freedoms at each node is used (Friedman and Kosmatka 1993; Reddy 1997).

The displacement components $u$ and $w$ in Eq. (1) will be approximated using six mechanical nodal variables:

$w(x, t)=\sum_{i=1}^{n} N_{w i}(x) \forall_{i}(t)$

$\varphi_{x}(x, t)=\sum_{i=1}^{n} N_{\phi i}(x) \forall_{i}(t)$

where $\left(N_{w i}, N_{\phi i}\right)$ are respectively the shape functions (see "Appendix") and $\forall=\left[W_{1} \phi_{x 1}, W_{2} \phi_{x 2}\right]$ is element nodal displacements for $i$ th node.

Substituting Eqs. (15.a), (15.b) into Eq. (3), the generalized strain vectors $\{\varepsilon\}$ at any point within the element are obtained by

$\left\{\begin{array}{l}\varepsilon_{x x} \\ \gamma_{x z}\end{array}\right\}=\left[\begin{array}{l}{\left[B_{w}\right]} \\ {\left[B_{\phi}\right]}\end{array}\right]\{\forall\}$

where $\left[B_{w}\right]$ and $\left[B_{\phi}\right]$ are given in the "Appendix".

In the proposed model, the electric potential is a function of the length, it can be represented by:

$V^{e}(x)=\sum_{i=1}^{2} V_{i}^{e} \theta_{j}$.

\section{Numerical analysis}

Numerical analysis using the developed methodology is performed. The fitness function is developed to investigate the optimal shape of the beams. A flow chart for genetic algorithm is shown in Fig. 2.

Hence, the electric field intensity can be written as (Yu et al. 2009):

$E_{z}=\frac{1}{h_{a}}\left[1-\frac{x_{e}}{L_{e}} \frac{x_{e}}{L_{e}}\right]\left[\begin{array}{l}V_{1}^{e} \\ V_{2}^{e}\end{array}\right]$

The shape functions Eqs. (15a, 15b)-(18) are substituted into the kinetic and potential equations. After performing the integration of Hamilton's principle [Eq. (14)], the dynamic equation of the laminate beam can be expressed as: 


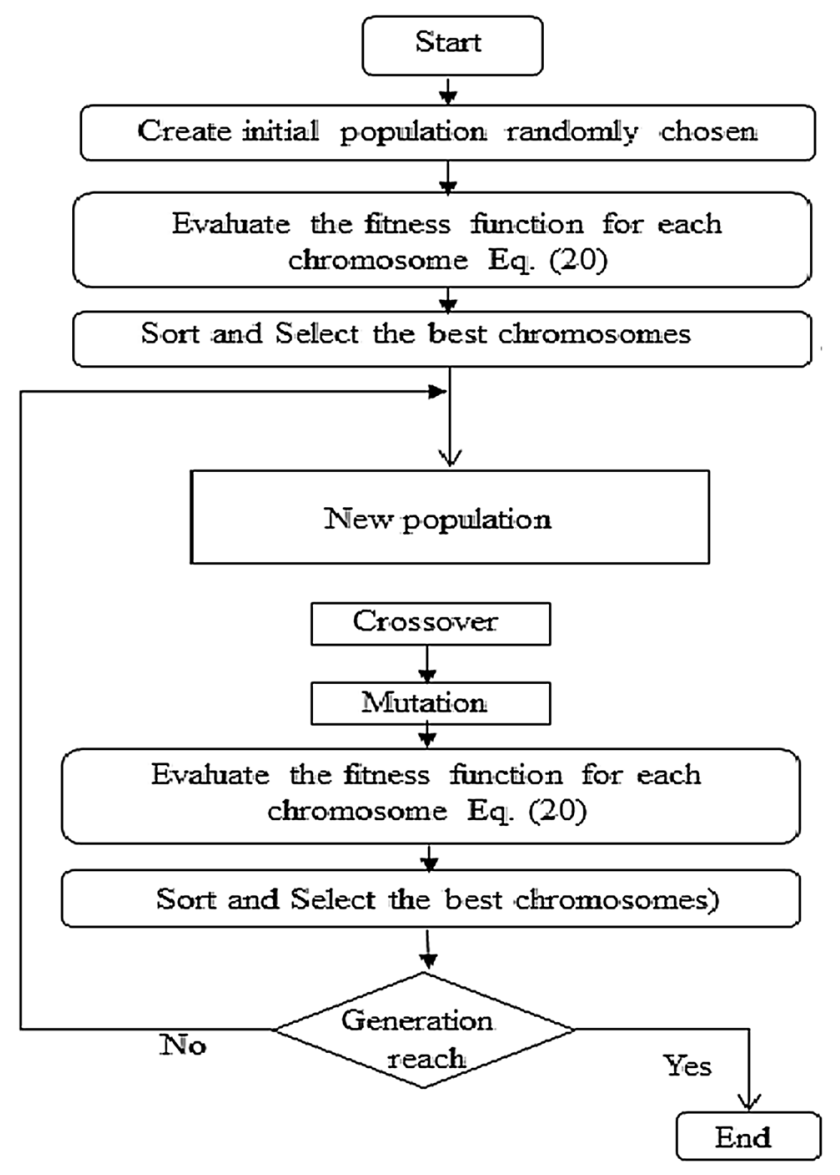

Fig. 2 Flow chart for genetic algorithm

$$
\left[M^{e}\right]\{\dot{\forall}\}+\left[K^{e}\right]\{\forall\}=\left\{f_{\text {mec }}^{e}\right\}+\left\{f_{\text {elec }}^{e}\right\}
$$

where $\{\ddot{\forall}\}$ and $\{\forall\}$ represent vector of double derivative of displacement and vector of displacement, respectively.

$\left[M^{e}\right]$ and represent the element mass and stiffness matrices corresponding to the vector of mechanical displacement.

$\left\{f_{\mathrm{mec}}^{e}\right\}$ and $\left\{f_{\mathrm{elec}}^{e}\right\}$ represent the external mechanical and electric forces (i.e., all the matrices are expressed in "Appendix").

A fitness function is developed as a sum of the errors at the node points. Chandrashekhara and Varadarajan (1997):

$J=\sum_{i=1}^{n} \forall_{i}-w_{d i}$.

\section{Results and discussions}

In the present section, numerical examples which are carried out for the shape control of beam with different boundary conditions, the shape control is provided using five piezoelectric actuators made of PZT G-1195 mounted

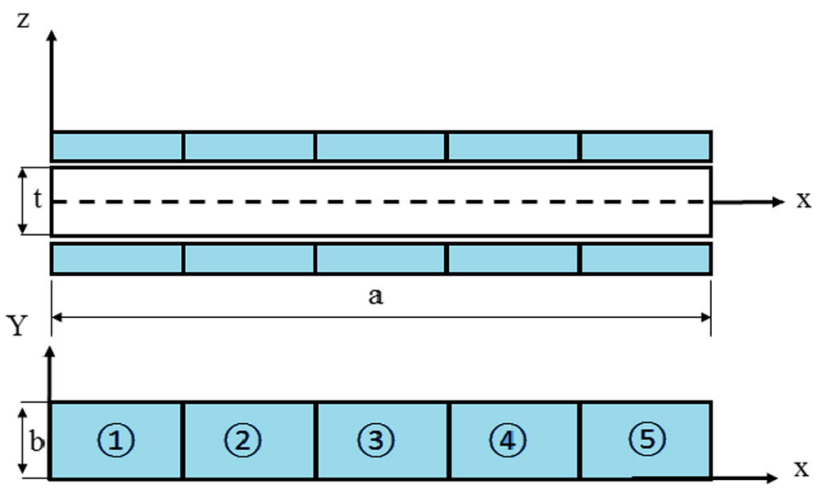

Fig. 3 A beam with surface-bonded piezoelectric actuators

at the top and bottom surfaces of the beam, see Fig. 3. All actuators are assumed to be perfectly bonded to the beam. The material properties and the geometrical dimensions of the beam and piezoelectric actuators are listed in Table 1.

In the first analysis case, a composite beam $(300 \mathrm{~mm} \times 40 \mathrm{~mm} \times 10 \mathrm{~mm})$ with five distributed piezoelectric patches on the top and the bottom of the beam with a thickness of $0.2 \mathrm{~mm}$ serving as actuators. Three cases of boundary conditions are considered (clamped-free (C-F), clamped-clamped (C-C), and simply supported (S$\mathrm{S})$. At first, we considered a clamped-free beam subjected to a fixed point loading equal to $4 \mathrm{~N}$ at the free end at $y=b / 2$. Each actuator is subject to constant actuation voltage of $200 \mathrm{~V}$.

The effect of the actuators position on the beam shape is studied for each single actuator. Each time one actuator has been activated, from Fig. 4 we noticed that the effect of actuation on beam shape is significant when the actuator is closer to the free end of the beam. The results were in good agreement with those presented by (Yuet al. 2009).

In the second example, we studied a clamped-clamped beam subjected to a fixed point loading equal to $4 \mathrm{~N}$ acting downward at the mid span of the beam $(x=a / 2, y=b / 2)$. Each actuator is subject to constant actuation voltage of $200 \mathrm{~V}$, as it can be seen in Fig. 5, the actuators are succeeded to reduce the shape of the beam, and the shape control is more significant when the actuator position is far away from the centre on the beam.

It is also seen that deflection is symmetrical means, the position of the actuators in the left and in the right of the applied force gives the same shape of the beam.

The last example in this case, a simply supported beam subjected to a fixed point loading equal to $4 \mathrm{~N}$ acting downward at the mid span of the beam $(x=a / 2, y=b / 2)$ is considered. Each actuator is subject to constant actuation voltage of $200 \mathrm{~V}$ as it can be seen in Fig. 6, the same notes as the case of $\mathrm{S}-\mathrm{S}$ beam can be noticed. 
Table 1 Material properties

\begin{tabular}{lll}
\hline Proprieties & T300/976 (Yu et al. 2009) & PZT G-1195 \\
\hline Young's modulus $E\left(N^{-2}\right)$ & $150 \times 10^{9}$ & $63 \times 10^{9}$ \\
Poisson's ratio & 0.3 & 0.3 \\
Shear modulus $G$ & $7.1 \times 10^{9}$ & $24.2 \times 10^{9}$ \\
Density $\rho\left(\mathrm{kg} \mathrm{m}^{-3}\right)$ & 1600 & 7600 \\
Piezoelectric constant $e_{31}\left(\mathrm{~cm}^{-2}\right)$ & - & 17.584 \\
Dielectric constant $\varepsilon_{33}\left(F \mathrm{~m}^{-2}\right)$ & - & $15.0 \times 10^{-9}$ \\
\hline
\end{tabular}

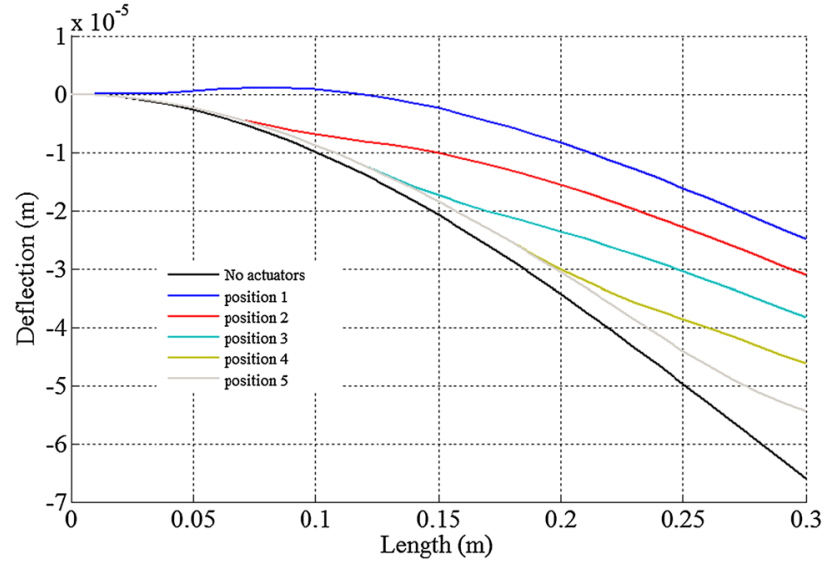

Fig. 4 The midline deflection of the C-F beam for each actuator position with $F=-4, V=200 \mathrm{v}$

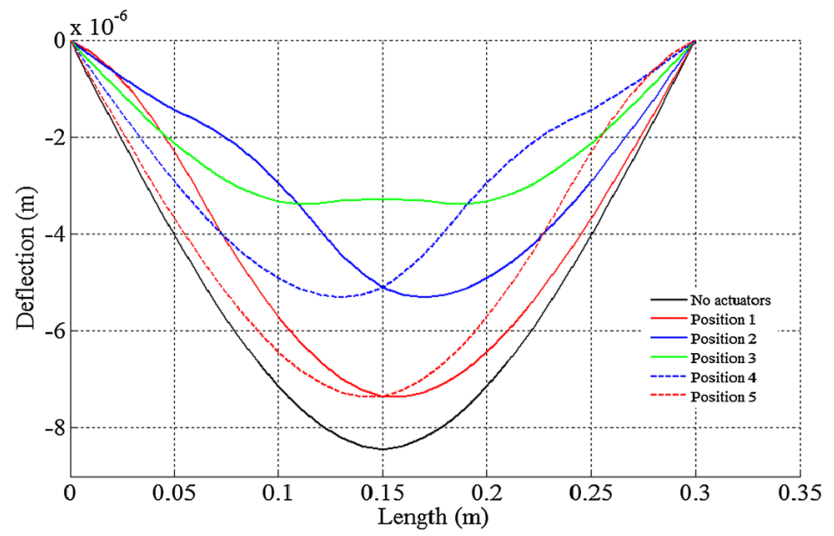

Fig. 5 The midline deflection of the C-C beam for each actuator position with $F=-4, V=200 \mathrm{v}$

The problem in shape control is to find the number and the required piezoelectric actuator voltage to maintain the desired shape. Several fitness functions are developed in the literature and in present paper based on the errors between the desired shape and the achieved shape. A fitness function is developed as a sum of the errors at the node points. Chandrashekhara and Varadarajan (1997):

$J=\sum_{i=1}^{n} \forall_{i}-w_{d i}$

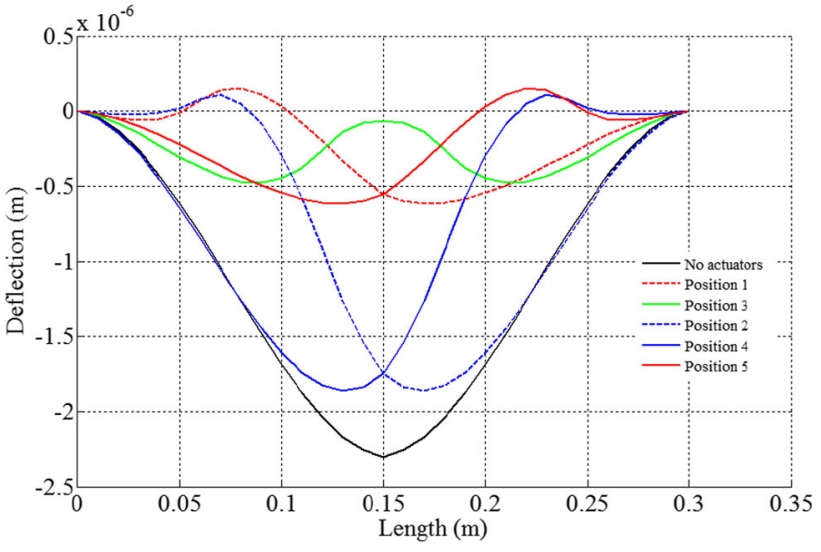

Fig. 6 The midline deflection of the S-S beam for each actuator position with $F=-4, V=200 \mathrm{v}$

where $w_{d}$ is the desired displacement of the $i$ th node and $\forall_{i}$ is the actual displacement.

The genetic algorithms (Haupt et al. 2004) are the most known and efficient method for the optimization problems, it is based on four key functions; selection, crossover and mutation and elitism. In the present study, the genetic algorithm is used to minimize the fitness function of Eq. (20) for the goal of finding the required voltage for a desired shape of the beam. The optimization procedure is performed in Matlab with following configuration: population size: 150 , crossover rate: 0.4 , generation number: 50. The actuator voltage limit is taken as $-200<V_{i}<+200$.

\section{Beam dimensions}

In the second analysis case, the numerical study is carried out for the case of composite beam with dimensions of $500 \mathrm{~mm} \times 40 \mathrm{~mm} \times 10 \mathrm{~mm}$. The beam is discretized into 30 elements. Each six element is covered by one actuator. The material proprieties are the same as the first case and it is given in Table 1. Actuator voltage and fitness function with respect to different boundary conditions are shown in Table 2. Responses obtained are shown in Figs. 7, 8, 9, respectively, for different support conditions of beam. 
Table 2 Actuator voltage and fitness function for different boundary conditions

\begin{tabular}{llll}
\hline Actuator voltage & C-F & C-C & S-S \\
\hline V1 & 13.93 & 84.70 & -187.6 \\
V2 & 10.03 & -16.95 & -90.02 \\
V3 & 8.19 & -43.99 & 230 \\
V4 & 4.17 & 18.76 & -43.35 \\
V5 & 1.41 & 85.70 & -195.12 \\
Best fitness & $2.68 \mathrm{e}-10$ & $2.90 \mathrm{e}-06$ & $2.51 \mathrm{e}-05$ \\
\hline
\end{tabular}

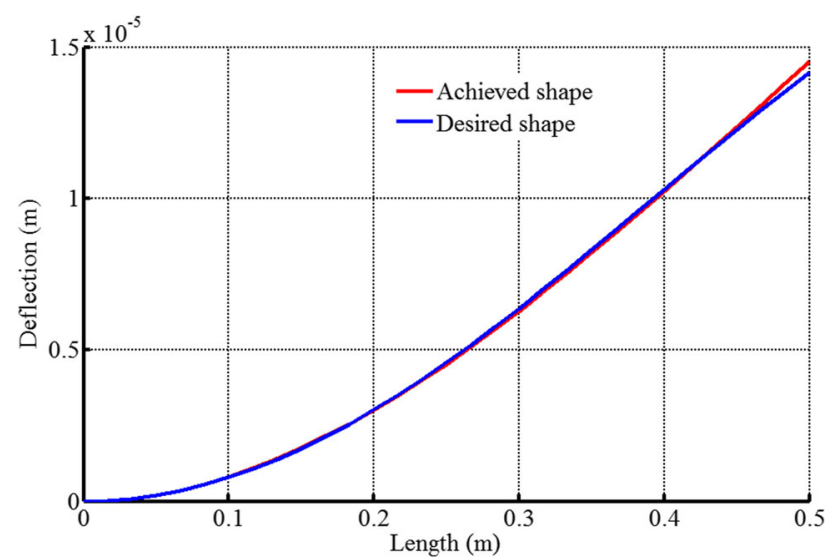

Fig. 7 The desired and achieved shape for the C-F beam

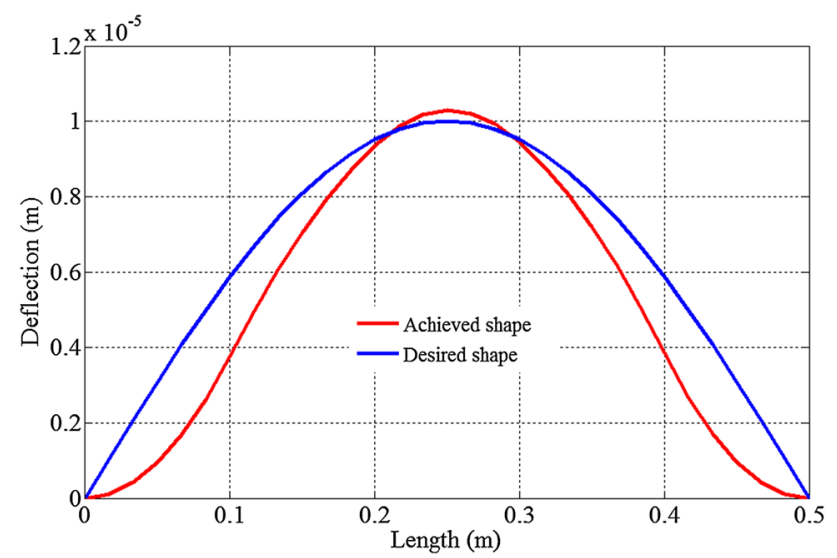

Fig. 8 The desired and achieved shape for the C-C beam

In the third analysis case, the numerical study is carried out for the case of composite beam with dimensions of $600 \mathrm{~mm} \times 40 \mathrm{~mm} \times 10 \mathrm{~mm}$. The beam is discretized into 30 elements. Each six element is covered by one actuator. The material proprieties are the same as the first case and it is given in Table 1. For this beam Actuator voltage and fitness function with respect to different boundary conditions are shown in Table 3.

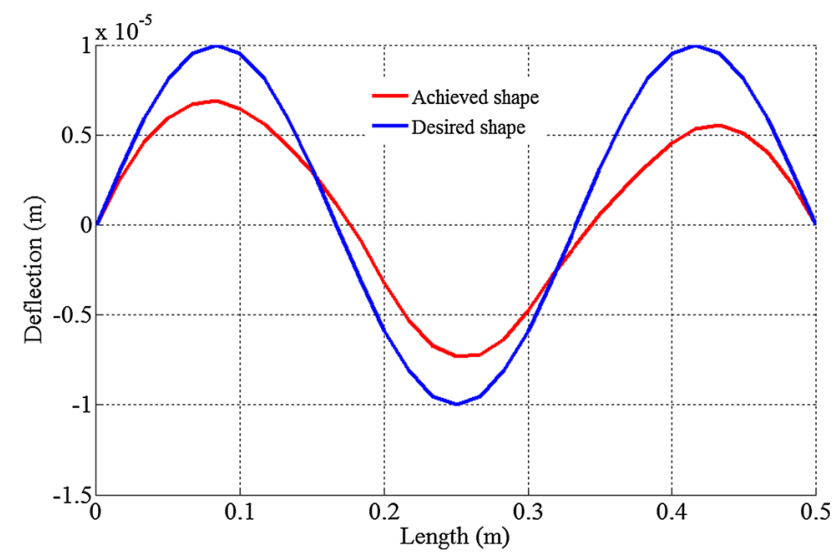

Fig. 9 The desired and achieved shape for the S-S beam

Table 3 Actuator voltage and fitness function for different boundary conditions

\begin{tabular}{llll}
\hline Actuator voltage & C-F & C-C & S-S \\
\hline $\mathrm{V}_{1}$ & 8.44 & 58.79 & -95.99 \\
$\mathrm{~V}_{2}$ & 9.66 & 3.56 & -97.93 \\
$\mathrm{~V}_{3}$ & 5.55 & 20.36 & 199.90 \\
$\mathrm{~V}_{4}$ & 1.42 & 48.36 & -61.02 \\
$\mathrm{~V}_{5}$ & -0.24 & 158.64 & -135.11 \\
Best fitness & $4.96 \mathrm{e}-8$ & $6.77611 \mathrm{e}-06$ & $1.21 \mathrm{e}-05$ \\
\hline
\end{tabular}

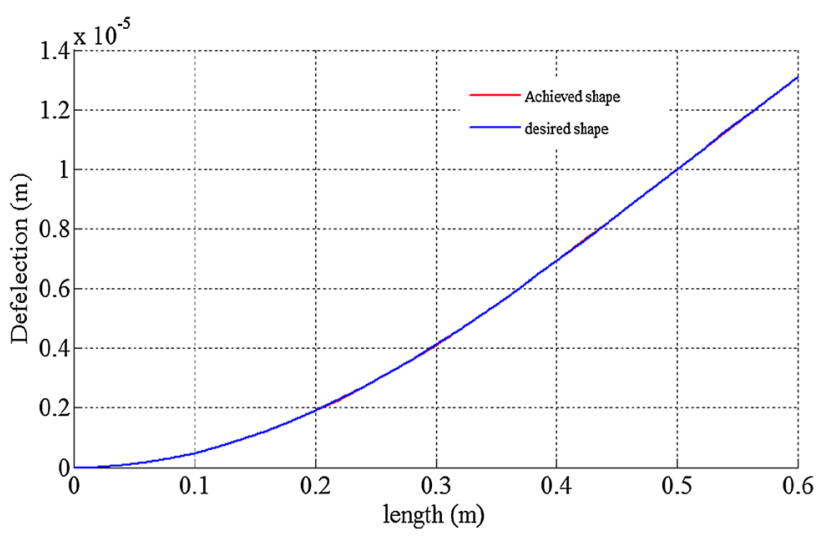

Fig. 10 The desired and achieved shape for the C-F beam

Figure 10 presents the desired and the achieved shape of the C-F beam. In this case, the desired deflection is taken as $W_{d}=1 e^{-5} \times(1-\cos (\pi x / L)$ where $L$ is the length of the beam. The required voltage and the fitness function value obtained from the GA optimization are presented in Table 3. It can be noticed that the required actuator voltage decreases as the actuator position is far away from the clamped edge. 


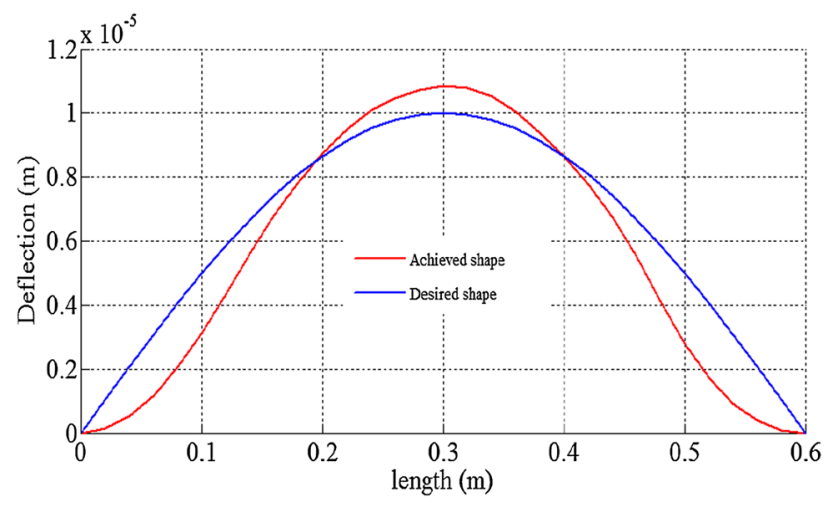

Fig. 11 The desired and achieved shape for the C-C beam

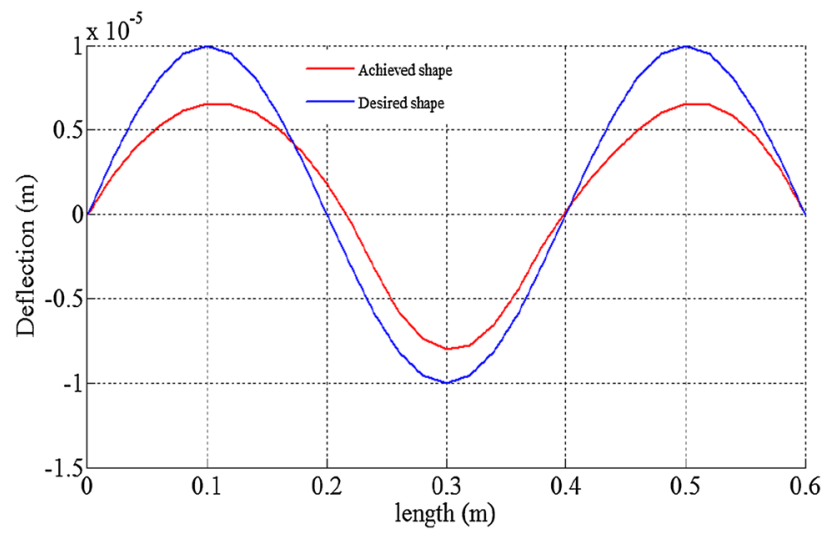

Fig. 12 The desired and achieved shape for the S-S beam

As a second example, a C-C beam is considered. The desired shape is assumed to be $W_{d}=1 e^{-5} \times(\cos (-\pi / 2+\pi x / L)$.

The required voltage and the corresponding fitness obtained by GA optimization technique are obtained. Hence, the achieved shape corresponding to those voltages is shown in Fig. 11. As it can be seen for the Figs. 11 and 12. A good response is observed between the achieved and desired shape.

In the last example, a simply supported $(\mathrm{S}-\mathrm{S})$ beam is considered. The desired shape is taken to be $W_{d}=1 e^{-5} \times \sin (3 \pi \times \pi x / L)$.

The required voltage obtained by GA optimization technique is presented in Table 3 for this also. The achieved shape corresponding to those voltages is shown in Fig. 11. As it can be seen from Fig. 11, a good response is obtained between the achieved and desired shape.

\section{Conclusions}

In the present paper, a methodology using finite element and genetic algorithms is proposed to investigate the shape control of composite beam with surface-mounted piezoelectric actuators. Three different geometry of beams are examined for the optimal shape control with different boundary condition and loading using presented genetic algorithm technique. The numerical investigation reveals the following points:

1. For the case of $\mathrm{C}-\mathrm{F}$ beam, the effect of actuation on beam shape is significant when the actuator is closer to the free end of the beam. For the case of C-C and S-S beam, the shape control is more significant when the actuator position is far away from the centre of the beam it is also seen that deflection is symmetrical.

2. An optimization of the required voltage actuation to achieve a desired shape is developed based on genetic algorithm; different cases of a desired function are presented for the case of composite beam with three boundary conditions.

Open Access This article is distributed under the terms of the Creative Commons Attribution 4.0 International License (http://crea tivecommons.org/licenses/by/4.0/), which permits unrestricted use, distribution, and reproduction in any medium, provided you give appropriate credit to the original author(s) and the source, provide a link to the Creative Commons license, and indicate if changes were made.

\section{Appendix: Stiffness coefficients of the laminated plate according to the higher-order shear defor- mation theory}

$$
\begin{aligned}
{\left[N_{w}\right]^{T}=} & {\left[\begin{array}{l}
\frac{1}{(1+k)}\left\{2 \xi^{3}-3 \xi^{2}-k \xi+(1+k)\right\} \\
-\frac{L_{e}}{(1+k)}\left\{\xi^{3}-\left(2+\frac{k}{2}\right) \xi^{2}+\left(1+\frac{k}{2}\right) \xi\right\} \\
-\frac{1}{(1+k)}\left\{2 \xi^{3}-3 \xi^{2}-k \xi\right\} \\
-\frac{L_{e}}{(1+k)}\left\{\xi^{3}-\left(1-\frac{k}{2}\right) \xi^{2}+\left(\frac{k}{2}\right) \xi\right\}
\end{array}\right] } \\
{\left[N_{w}\right]^{T}=} & {\left[\begin{array}{l}
-\frac{6}{(1+k)}\left\{\xi^{2}-\xi\right\} \\
\frac{1}{(1+k)}\left\{3 \xi^{2}-(4+k) \xi+(1+k)\right\} \\
\frac{6}{(1+k)}\left\{\xi^{2}-\xi\right\} \\
\frac{1}{(1+k)}\left\{2 \xi^{2}-(2-k) \xi\right\}
\end{array}\right] }
\end{aligned}
$$

with

$$
k=\frac{12(\mathrm{EI})}{(\mathrm{GA}) L_{e}^{2}} \text { and } \xi=\frac{x}{L_{e}}
$$




$$
\begin{aligned}
& {\left[B_{w}\right]^{T}=z \frac{\partial N_{\phi}}{\partial x}=\left[\begin{array}{c}
-\frac{6 z}{(1+k) L_{e}}\left(\frac{2 x}{L_{e}^{2}}-\frac{1}{L_{e}}\right) \\
\frac{z}{(1+k)}\left(\frac{6 x}{L_{e}^{2}}-\frac{4+k}{L_{e}}\right) \\
\frac{6 z}{(1+k) L_{e}}\left(\frac{2 x}{L_{e}^{2}}-\frac{1}{L_{e}}\right) \\
\frac{z}{(1+k)}\left(\frac{6 x}{L_{e}^{2}}-\frac{2-k}{L_{e}}\right)
\end{array}\right]} \\
& {[B \phi]^{T}=N_{\phi}+\frac{\partial N_{w}}{\partial x}=\left[\begin{array}{c}
-\frac{k}{(1+k) L_{e}} \\
\frac{k}{2(1+k)} \\
\frac{k}{(1+k) L_{e}} \\
\frac{k}{2(1+k)}
\end{array}\right]} \\
& {\left[M^{e}\right]=\int_{0}^{L_{e}}\left[\begin{array}{l}
N_{w} \\
N_{\phi}
\end{array}\right]^{T}\left[\begin{array}{ll}
l_{1} & 0 \\
0 & l_{3}
\end{array}\right]\left[\begin{array}{l}
N_{w} \\
N_{\phi}
\end{array}\right] \mathrm{d} x} \\
& {\left[K^{e}\right]=\left[K_{u u}^{e}\right]+\left[K_{u v}^{e}\right]\left[K_{v v}^{e}\right]\left[K_{v u}^{e}\right]}
\end{aligned}
$$

With

$$
\begin{aligned}
& {\left[K_{v u}^{e}\right]=\left[K_{u v}^{e}\right]^{T}} \\
& {\left[K_{u u}^{e}\right]=\int_{0}^{L_{e}}\left[\begin{array}{c}
B_{w} \\
B_{\phi}
\end{array}\right]^{T}\left[\begin{array}{cc}
\mathrm{EI} & 0 \\
0 & \mathrm{GA}
\end{array}\right]\left[\begin{array}{c}
B_{w} \\
B_{\phi}
\end{array}\right] \mathrm{d} x} \\
& {\left[K_{u v}^{e}\right]=\int_{0}^{L_{e}}\left[B_{w}\right]^{T} e_{31}-\frac{1}{\mathrm{nt}_{p}}\left[\left(1-\frac{x_{e}}{L_{e}}\right) \frac{x_{e}}{L_{e}}\right] \mathrm{d} A_{p} \mathrm{~d} x} \\
& {\left[K_{v v}^{e}\right]=\int_{0}^{L_{e}} \int_{A_{p}}^{L_{p}}-\frac{1}{\left(\mathrm{nt}_{p}\right)^{2}} \times\left[\left(\frac{1-\frac{x_{e}}{L_{e}}}{\frac{x}{e}_{e}}\right) \epsilon_{33}\left[\left(1-\frac{x_{e}}{L_{e}}\right) \frac{x_{e}}{L_{e}}\right]\right] \mathrm{d} A_{p} \mathrm{~d} x} \\
& \text { And }\left\{f_{\text {mec }}^{e}\right\}=\int_{0}^{L_{e}}\left[\begin{array}{c}
N_{w} \\
N_{\phi}
\end{array}\right]\left[\begin{array}{c}
q \\
0
\end{array}\right] \mathrm{d} x \\
& \left\{f_{\text {ele }}^{e}\right\}=\int_{0}^{L_{e}}\left[\begin{array}{c}
B_{w} \\
B_{\phi}
\end{array}\right]\left[\begin{array}{c}
M^{\mathrm{el}} \\
0
\end{array}\right] \mathrm{d} x .
\end{aligned}
$$

\section{References}

Agrawal BN, Treanor KE (1999) Shape control of a beam using piezoelectric actuators. Smart Mater Struct 8:729-740

Aldraihem OJ, Khdeir AA (2000) Smart beams with extension and thickness-shear piezoelectric actuators. Smart Mater Struct 9:1-9

Aldraihem OJ, Wetherhold RC, Singh T (1997) Distributed control of laminated beams: Timoshenko vs. Euler-Bernoulli theory. J Intell Mater Syst Struct 8:149-157
Azrar L, Belouettar S, Wauer J (2008) Nonlinear vibration analysis of actively loaded sandwich piezoelectric beams with geometric imperfections. Comput Struct 86:2182-2191

Bajoria KM, Wankhade RL (2012) Free vibration of simply supported piezolaminated composite plates using finite element method. Adv Mater Res 587:52-56

Bajoria KM, Wankhade RL (2015) Vibration of cantilever piezolaminated beam with extension and shear mode piezo actuators. Proc SPIE Active Passive Smart Struct Integr Syst 9431(943122):1-6

Beheshti-Aval SB, Shahvaghar-Asl S, Lezgy-Nazargah M, Noori M (2013) A finite element model based on coupled refined highorder global-local theory for static analysis of electromechanical embedded shear-mode piezoelectric sandwich composite beams with various widths. Thin wall struct 72(2013):139-163

Bendine K, Wankhade RL (2016) Vibration Control of FGM Piezoelectric Plate Based on LQR Genetic Search. Open J Civil Eng 6(1):1-7

Bruch J Jr, Sloss J, Adali S, Sadek I (2000) Optimal piezo-actuator locations/lengths and applied voltage for shape control of beams. Smart Mater Struct 9:205-211

Chandrashekhara K, Varadarajan S (1997) Adaptive shape control of composite beams with piezoelectric actuators. J Intell Mater Syst Struct 8(2):112-124

Crawley EF, Anderson EH (1990) Detailed models of the piezoceramic actuation for beams. J Intell Mater Syst Struct 1:4-25

da Mota Silva S, Ribeiro R, Rodrigues JD, Vaz MAP, Monteiro JM (2004) The application of genetic algorithms for shape control with piezoelectric patches-an experimental comparison. Smart Mater Struct 13(1):220-226

Dhonthireddy P, Chandrashekhara K (1996) Modeling and shape control of composite beams with embedded piezoelectric actuators. Compos Struct 35:237-244

Dhuri KD, Seshu P (2009) Multi-objective optimization of piezoactuator placement and sizing using genetic algorithm. J Sound Vib 323:495-514

Elshafei MA, Alraiess F (2013) Modeling and analysis of smart piezoelectric beams using simple higher order shear deformation theory. Smart Mater Struct 22(3):35006

Faria AR, Almeida SFM (1999) Enhancement of pre-buckling behavior of composite beams with geometric imperfections using piezoelectric actuators. Compos B 30:43-50

Friedman Z, Kosmatka JB (1993) An improved two-node Timoshenko beam finite element. Comput Struct 47(3):473-481

Fuller CC, Elliott S, Nelson PA (1996) Active control of vibration. Academic Press, Cambridge

Hadjigeorgiou EP, Stavroulakis GE, Massalas CV (2006) Shape control and damage identification of beams using piezoelectric actuation and genetic optimization. Int J Eng Sci 44(7):409-421

Han JH, Rew KH, Lee I (1997) An experimental study of active vibration control of composite structures with a pizo-ceramic actuator and a piezo-film sensor. Smart Mater Struct 6(5):549-558

Irschik H (2002) A review on static and dynamic shape control of structures by piezoelectric actuation. Eng Struct 24(1):5-11

Haupt RL, Haupt SE (2004) Practical genetic algorithms. John Wiley \& Sons, Hoboken

Kang YK, Park HC, Kim J, Choi SB (2002) Interaction of active and passive vibration control of laminated composite beams with piezoceramic sensors/actuators. Mater Des 23:277-286

Kayacik Ö, Bruch JC, Sloss JM, Adali S, Sadek IS (2008) Integral equation approach for piezopatch vibration control of beams with various types of damping. Comput Struct 86:357-366

Kekana M, Tabakav P, Walker M (2003) A shape control model for piezo-elastic structures based on divergence free electric displacement. Int J Solids Struct 40:715-727 
Kirchhoff GR (1850a) Uber das gleichgewicht und die bewegung einer elastischen scheibe. J Reine Angew Math (Crelle) 40:51-88

Kirchhoff GR (1850b) Uber die uchwingungen einer kriesformigen elastischen scheibe Poggendorffs. Annalen 81:58-264

Krommer M, Irschik H, Zellhofer M (2008) Design of actuator networks for dynamic displacement tracking of beams. Mech Adv Mater Struct 15:235-249

Kucuk I, Sadek IS, Zeini E (2011) Optimal vibration control of piezolaminated smart beams by the maximum principle. Comput Struct 89(9-10):744-749

Mindlin RD (1951) Influence of rotatory inertia and shear on flexural motions of isotropic, elastic pates. ASME J Appl Mech 18:31-38

Onoda J, Hanawa Y (1993) Actuator placement optimization by genetic and improved simulated annealing algorithms. AIAA J 31:1167-1169

Pan J, Hansen CH, Snyder SD (1992) A study of the response of a simply supported beam to excitation by a piezoelectric actuator. J Intell Mater Syst Struct 3:3-16

Reddy JN (1997) On locking-free shear deformable beam finite elements. Comput Methods Appl Mech Eng 149(1):113-132

Soares CMM, Soares CAM, Correia VMF (1999) Optimal design of piezolaminated structures. Compos Struct 47:625-634

Takács G, Rohal'-Ilkiv B (2012) Model predictive vibration control: efficient constrained MPC vibration control for lightly damped mechanical structures. Springer Science \& Business Media, Berlin

Thomson SP, Loughlan J (1995) The active buckling control of some composite column using piezoceramic actuators. Compos Struct 32:59-67
Tzou HS, Tseng CI (1990) Distributed piezoelectric sensor/actuator design for dynamic measurement/control of distributed parameter systems: a piezoelectric finite element approach. J Sound Vib 138(1):17-34

Wang Q (2002) On buckling of column structures with a pair of piezoelectric layers. Eng Struct 24:199-205

Wankhade RL, Bajoria KM (2012) Stability of simply supported smart piezolaminated composite plates using finite element method. Proc Int Conf Adv Aeronaut Mech Eng AME 1:14-19

Wankhade RL, Bajoria KM (2013a) Buckling analysis of piezolaminated plates using higher order shear deformation theory. Int $\mathrm{J}$ Compos Mater 3:92-99

Wankhade RL, Bajoria KM (2013b) Free vibration and stability analysis of piezolaminated plates using finite element method. Smart Mater Struct 22(125040):1-10

Wankhade RL, Bajoria KM (2016) Shape control and vibration analysis of piezolaminated plates subjected to electro-mechanical loading. Open J Civil Eng 6:335-345

Wankhade RL, Bajoria KM (2017) Numerical optimization of piezolaminated beams under static and dynamic excitations. J Sci Adv Mater Devices 2(2):255-262

Yu Y, Zhang XN, Xie SL (2009) Optimal shape control of a beam using piezoelectric actuators with low control voltage. Smart Mater Struct 18(9):95006

\section{Publisher's note}

Springer Nature remains neutral with regard to jurisdictional claims in published maps and institutional affiliations. 